\title{
Elder self-neglect: research and practice
}

This article was published in the following Dove Press journal:

Clinical Interventions in Aging

8 June 2017

Number of times this article has been viewed

\section{XinQi Dong}

Rush Institute for Healthy Aging, Rush University Medical Center, Chicago, IL, USA
Correspondence: XinQi Dong Rush Institute for Healthy Aging, Rush University Medical Center, 1645 West Jackson Boulevard, Suite 675, Chicago, IL 606 I2, USA

Tel + I 3 I 29423350

Fax + I 312942286 I

Email xinqi_dong@rush.edu
Abstract: Elder self-neglect is a global public health and human rights issue that threatens older people's health and safety. It commonly refers to refusal or failure to provide oneself with care and protection in areas of food, water, clothing, hygiene, medication, living environments, and safety precautions. While prevalent, the status of self-neglecting individuals remains largely unclear, in particular within community-dwelling populations. By reviewing the epidemiology of elder self-neglect (definition, prevalence, risk factors, and consequences) to date, the present paper identifies key research gaps such as methodological inconsistency in case identification and measurement, and study designs that are inadequate to determine risk factors of self-neglect. More importantly, in light of the rapidly growing older population, relevant stakeholders (researchers, healthcare providers, social service providers, legal professionals, community organizations, and policymakers) must be prepared for an expected increasing number of selfneglect cases and enlarging scope of the problem. Hence, in this article, I present an overview regarding the management issues of elderly self-neglect related to the detection, assessment, reporting and referral, and decision-making capacity. Based on the current literature, the paper is aimed to explore the present knowledge and challenges, and how they can pave the way for solutions to self-neglect research, practice, and policy.

Keywords: elderly self-neglect, elder abuse, self-neglect future directions

\section{Introduction}

Elder self-neglect is a public health issue that affects millions of older people each year. ${ }^{1}$ It manifests itself in an older person in the form of refusal or failure to provide himself/herself with adequate food, water, clothing, shelter, personal hygiene, medication, and safety precautions. ${ }^{2}$ In US, self-neglect has been the primary type $(41.9 \%)$ of elder abuse (EA) cases reported to the Adult Protective Services (APS). ${ }^{3}$

Although there is a growing body of research which examines self-neglect, there is a lack of information on how to systematically estimate its prevalence. Recent population studies have shown various prevalence estimates in part due to different study populations and methodological inconsistency, such as inconsistent operational definitions and measurements. A study on 1,023 older adults living alone in a metropolitan area in South Korea indicated that $22.8 \%$ of the participants had some form of self-neglect. ${ }^{4}$ A study on 5,519 older adults from the Chicago Health and Aging Project (CHAP) found a prevalence of $21.7 \%$ among African-Americans and 5.3\% among whites. ${ }^{5,6}$ A study of self-neglect within a cohort of 3,159 community-dwelling Chinese older adults in Chicago found that the overall prevalence of self-neglect was $29.11 \%$, with $18.24 \%$ being classified as mild and $10.87 \%$ as moderate to severe. ${ }^{7}$

It is evident that self-neglect is associated with adverse outcomes concerned to older people's physical and psychological well-being, mortality, and health care utilization. ${ }^{8-12}$ In light of the rapidly growing older population, relevant organizations and individuals in social and medical field (eg, social service agencies, community organizations, health 
care providers, social workers, and attorneys) must be able to manage an expected increasing number of self-neglect cases and enlarging scope of the problem. Hence, in this article, I present an overview regarding the potential to address selfneglect by exploring existing challenges based on the current literature and how they can pave the way for solutions regarding self-neglect research, practice, and policy.

\section{Definition}

The 2010 Elder Justice Act (EJA) defined self-neglect as the "inability, due to physical or mental impairment or diminished capacity, to perform essential self-care", ${ }^{3}$ but different conceptual definitions can be found across nations, states, and organizations. Importantly, there is no consensus on an operational definition, which greatly impedes a systematic understanding of self-neglect. Currently, case identification criteria, which determine the self-neglecting behaviors, is varied: either using an "any or none" criteria or more restrictive ones. In 2014, the possible impact of divergent criteria was demonstrated by a study in which the author derived different prevalence rates of EA within the same cohort ranging from $13.9 \%$ to $25.8 \%$ by using five different case identification criteria. ${ }^{13}$

Moreover, a variety of measurements of self-neglect have been used. For example, Dong used a 27-item Chicago self-neglect scale to assess self-neglect in a US Chinese population. ${ }^{14}$ The Illinois Department on Aging used a 45 -item home assessment instrument for the CHAP study. ${ }^{10}$ In a study conducted in South Korea, Lee and Kim used five items of the Screening Scale for Elder Abuse. ${ }^{4}$ In addition, this inconsistency extends to the typology of self-neglect. For instance, Burnett et al categorized self-neglect into four subtypes of physical and medical neglect, environmental neglect, global neglect, and financial neglect, ${ }^{15}$ whereas Dong et al used five phenotypes: hoarding, personal hygiene, the house needs repair, unsanitary conditions, and inadequate utility. ${ }^{5}$ These common variations in conceptual and operational definitions have greatly obfuscated the comparability and limited the impact of the current research related to self-neglect.

\section{Risk factors}

Risk factors leading to elder self-neglect remain unclear due to the lack of rigorous longitudinal investigations that can validate putative risk factors associated with self-neglect from previous cross-sectional investigations. While insufficient to understand the issues of risk factors, however, existing cross-sectional studies are valuable in their contribution to our knowledge of associated factors of self-neglect. Inconsistent trends have been observed regarding the relationship of socioeconomic status and self-neglect. Studies found that people with fewer economic resources are more likely to experience self-neglect. ${ }^{16,17}$ However, some researchers have suggested that self-neglect affects older adults across every education and economic strata. ${ }^{18,19}$ In addition, cognitive impairment, physical disability, and psychological distress have been linked to increased risk of self-neglect. The authors of CHAP study observed that diminished executive function, global cognitive function, and physical function (tested and self-reported) were associated with increased presence and severity of self-neglect. ${ }^{16,20}$ A longitudinal study on 2,812 older adults in the Established Populations for Epidemiologic Studies of the Elderly (EPESE) cohort found that greater depressive symptoms were associated with more self-neglect reports to APS. ${ }^{21}$ Older adults who had higher levels of depressive symptoms or a lack of family support in South Korea were more likely to have self-neglect behaviors. ${ }^{4}$ In addition, older adults with a smaller social network and less social engagement were more likely to self-neglect. ${ }^{22}$ Longitudinal studies in diverse populations with adequate sample size are needed to validate the causal relationships between these associated factors and self-neglect.

\section{Consequences}

Elder self-neglect has been linked to devastating outcomes on older adults' physical and psychological well-being, higher mortality rate, and increased health care services utilization. Evidence has shown that self-neglect is associated with higher levels of cognitive and physical impairments, ${ }^{23,24}$ and self-neglecting older adults are more likely to experience nutritional deficiency and medical non-adherence. ${ }^{25}$ The New Haven EPESE study found that people who selfneglect have increased risk of all-cause mortality. ${ }^{12}$ Studies of the CHAP cohort found that self-neglect is associated with a significantly increased risk of 1 -year mortality. ${ }^{26}$ For cause-specific mortality, self-neglect was found associated with increased mortality risks in cardiovascular, pulmonary, neuropsychiatric, endocrine or metabolic, and neoplasmrelated death. ${ }^{26}$ Correspondingly, such adverse outcomes and other medical comorbidities associated with self-neglect may result in greater health care and social service utilization. Recent investigations suggested that self-neglecting elders have higher rates of nursing home placement, emergency department admission, hospitalization use and readmission, hospice use, and long-term nursing home placement. ${ }^{9,10,27}$

\section{Management \\ Detection}

Given the known increased use of these services and resources associated with self-neglect, health and social 
service professionals are well situated to detect the presence of self-neglecting behaviors of an older person. While this requires comprehensive assessments for health, welfare, and safety, only a limited number of screening and detection tools exist to determine the presence of self-neglect, and most of which have not been tested for reliability and validity. To my knowledge, the Chicago Self-Neglect Scale and the Texas Self-Neglect Scale are the only two measurements that have been tested psychometrically, ${ }^{28}$ and a comprehensive list of other measures can be found elsewhere. ${ }^{29}$ The Chicago scale evaluates self-neglect in domains of hoarding, personal hygiene, house in need of repair, unsanitary conditions, and inadequate utilities. ${ }^{6}$ The Texas scale examines living conditions, financial status, physical/medical status, mental status, and social interaction/support. ${ }^{30}$

Compared to the other cases of EA, signs of self-neglect might be subtle, which calls for the development of a predictive index regarding the onset of self-neglect in different settings. While so far such tool does not exist, professionals involved in providing care and services to older adults need to be able to identify signs of associated adjunct and risk factors, particularly when it is difficult to obtain authorization for access to a private residence (the Chicago Self-Neglect Scale and the Texas Self-Neglect Scale both require in-home investigations). Common predisposing signs leading to the incapability of executing self-care and protection majorly appear as diminished functional and cognitive statuses, health status, inadequate social support, and a presence of psychosocial distress., ${ }^{4,20,21}$ For example, a physician might meet an older person regularly during clinical appointments but is unable to assess selfneglect behaviors and conditions such as house conditions, hoarding behaviors, and inadequate utilities. In addition to observations of personal hygiene (eg, hair, nails, clothes, wounds, odors, weight loss, etc.), the physician ought to be conscious of self-neglecting signs such as changes in nutrition, hydration, cognition, physical function, mental health, financial status, missed medical appointments, and medication refills.

Researchers and health care providers should prioritize addressing barriers in the detection of self-neglect in order to help millions of underserved self-neglect victims. Following are some of the major barriers: 1) inadequate knowledge and awareness of self-neglect; 2) limited supporting resources and systems, and lack of standardized protocols and training for personnel who are best poised to intervene; 3) inadequate evidence determining risk factors and adjuncts that can predict the onset of self-neglect; and 4) lack of reliable, valid, and culturally appropriate assessment tool for self-neglect.

\section{Assessment}

Once there is a suspected or known case of self-neglect, there is a need for more comprehensive evaluation that combines clinical assessments and psychological, social, behavioral, environmental, and cultural evaluations of an individual. These assessments will be able to determine the need for assistance, prioritize immediate needs, and assess available resources. ${ }^{31}$ Due to the complex nature of self-neglect behaviors, a multidisciplinary approach is required to perform the assessments (eg, by physicians, nurses, therapists, discharge planners, social workers, legal agencies, social agencies, criminal justice system, faith-based community organizations, etc.). For instance, evaluation of the home, social, and community environments of a senior might elucidate issues concerning access to public gathering locations, social isolation, and available community-level resources. In the medical setting, physicians can evaluate needs for immediate treatment and assistance, and treat health consequences resulting from self-neglecting behaviors. While providing care and services, nurses may have the best chance to observe several conditions that indicate the presence of self-neglect such as nutrition, hydration, injuries, and levels of frailty. Hospital discharge planners might be able to engage family members of a self-neglecting senior to take actions. Stepwise guidance needs to be developed in organizational levels to help professionals to work collectively to confirm neglect, document impaired capacity, review medications and medical conditions, and coordinate with the family to take actions. ${ }^{1}$

\section{Reporting and referral}

According to the World Health Organization report, only four Atlantic provinces of Canada, Israel, and 43 states of the US mandate reporting cases of EA, ${ }^{32}$ which may not include reports of self-neglect. In addition to the aforementioned definitional ambiguity, there is no consensus about whether to classify self-neglect as a type of EA. This leads to variations of reporting system of self-neglect across countries and regions. In the US, most clinicians, social workers, mental health consultants, and other professionals are mandated to report a reasonable suspicion of EA cases including self-neglect to the APS. Under US statutes, the APS will then decide whether to conduct in-home investigations of the alleged self-neglect case. After a case is confirmed, it is vital that a team of multidisciplinary experts plan appropriate referrals, interventions, and treatments that are of the best interest of the self-neglecting individuals, but it is unclear if this process is properly executed.

One particular challenge in addressing a senior's selfneglect behaviors is the senior's own resistance to care and 
support. ${ }^{33}$ In terms of policy making, this raises a primary question of respect on persons regarding self-neglect: what is the optimal balance of autonomy of individuals and interference from society? In the US, mandatory reporters are "encouraged" to report "reasonable suspicion", which implements a preference for possible false reports (false positive) of self-neglect cases versus failure to report (false negative). Such strategy that allows a wider net when identifying potential victims could be adopted in other countries and regions with respect to the policy making process. Further, more tailored strategies need to be developed in response for each stage of self-neglect severity, that is, concrete reporting strategies and regulations for early signs and more advanced circumstances. $^{34}$

\section{Decision-making capacity}

Decision-making capacity is a person's ability to understand or appreciate the current situation or problem, the nature of the proposed action including its risks and benefits, and he or she must be able to communicate this understanding to others. ${ }^{1}$ In some cases, a substantial lack of self-awareness of one's self-neglecting behaviors and conditions might indicate that individual's lack of the capacity to make decisions regarding his/her self-care and protection. Naik et al distinguished the capacity into dimensions of decisional capacity and executive capacity. Decisional capacity refers to "the ability to make decisions for oneself or extending that power to another individual when it is impaired". Executive capacity involves "the ability to put one's decision into effect either alone or by delegating those responsibilities to another more physically able individual". ${ }^{24}$

In cases of self-neglect, a senior with undiagnosed and untreated medical conditions might have intact decisional capacity that allows him/her to refuse necessary care and support. However, the ability to execute a particular activity might have been diminished, which would leave the individual in risky and dangerous situations. Therefore, a key ethical dilemma surrounding self-neglect management is under which circumstances the medical community, family, and society should be allowed to override the will of an individual who self-neglects.

Furthermore, for professionals and agencies that manage self-neglect cases, decision-making process is further complicated by a variety of related factors such as a person's previous experience, habits, values, attitudes, opinions, and cultural beliefs. In addition, decision-making capacity can fluctuate over time and be influenced by conditions such as cognitive disorders, psychiatric disorders, mental retardation, comorbid medical conditions, medication side-effects, and physical impairment or disability. ${ }^{1}$ Without a situational and culture-specific understanding of these factors, it is difficult to protect older people and simultaneously avoid unnecessary infringements of their rights in a best possible way.

Researchers have strived for solutions to these complex obstacles. Dong and Gorbien's article emphasized the essential of balancing obligation for protection and respect for autonomy by asking task-specific and time-sensitive question - "is this particular person capable at this particular time of making this particular decision?" They also suggested strategies such as understanding multifaceted values of a self-neglecting senior, engaging multidisciplinary team, and conducting comprehensive geriatric assessment. ${ }^{1}$ Naik et al introduced a practical "articulate and demonstrate" framework that can be used by clinicians to identify impairments and needs for specific referrals, avoid unnecessary long-term care placement, and individualize interventional strategies. ${ }^{35}$ Other commonly used brief screening tests evaluating decision-making capacity are the Aid to Capacity Evaluation, the Hopkins Competency Assessment Test, and Understanding Treatment and Disclosure. ${ }^{28}$

The Mental Capacity Act 2005 enacted in England and Wales has exemplified a five-step legal framework to safeguard people's rights to make decisions whenever possible, and to protect those who lack the capacity to do so. The first three stepwise principles are to empower decision-making process when lack of capacity has not been determined: 1) assuming everyone has the capacity regardless of particular medical condition or disability;2) making every effort to support people making decisions; and 3) avoiding treating someone as lacking the capacity because their decisions seem unwise according to the standards of others. After the lack of capacity has been identified, people who act on behalf of the person must 1) ensure that everything is done in his/her best interests and 2) minimize interference with his/her rights. ${ }^{36}$

\section{Prevention and intervention strategies}

The existing strategies of prevention and intervention for elder self-neglect need to be rigorously tested for their intentional benefits and potential harm because wellintentioned practices can result in adverse outcomes. For example, partially contradictory to the US Preventive Service Task Force's recommendation of universal intimate partner violence screening for women of childbearing age, a randomized clinical trial (RCT) conducted in 2009 found insufficient evidence of both effectiveness and harm of this 
tool. ${ }^{37}$ Rigorous experimental studies need to be conducted to test a variety of existing or emerging actions for elder justice such as advocacy service intervention, support groups, and community educational programs. ${ }^{38,39}$ Despite the paucity of empirical evidence of specific strategies, a multidisciplinary team approach with a robust system of collaboration, communication, and risk sharing is believed to be effective for self-neglect issues. ${ }^{40}$ Each part of the multidisciplinary team may focus on a specific area, that is, improving daily function, to ensure the safety of the elder, promote knowledge and understanding within a community, and keep efficient and transparent lines of communication. Medical teams, mental health professionals, community educational programs, social workers, and agencies of financial service must also be included to address the depth of self-neglect issues.

\section{Policy}

In the US, major steps have been made at the federal level to protect rights of older adults by the enactments of several statutes such as the Social Security Act, the Older Americans Act, and the EJA. In May 2013, the Iowa Department on Aging called attention to recognize self-neglect and develop corresponding strategies to help vulnerable citizens. ${ }^{41}$ In March 2011, the Senate Special Committee on Aging held a hearing: "Justice for All: Ending Elder Abuse, Neglect and Exploitation". ${ }^{42}$ In terms of federal spending, it was estimated that the US spent nearly 500 million US dollars on the APS agencies in 2004, where self-neglect was the most commonly reported case. ${ }^{3}$

Despite the efforts that have been made, institutional and structural strengths and supports are needed to be realized and implement the signed legislations. For example, several grant programs that have been authorized by the EJA have not been appropriated by federal funds. These grants are in support of the EA investigations, the APS programs, education, and employment for related workforce, ${ }^{43}$ which are extremely essential to the advancement of the self-neglect field. Continuous funding resources are needed in the field of self-neglect research and practices in community and health-care settings.

\section{Conclusion}

This review highlights the complexities of self-neglect research, which require collaborative efforts of the medical and legal community and society to protect the vulnerable population. Several putative risk factors of self-neglecting behaviors might provide implications for the strategies related to its detection, prevention, and intervention. In light of the rapidly growing aging population and the alarming effect of elder self-neglect, large longitudinal studies are needed to validate the associated risk and protective factors of self-neglect, and rigorously designed experimental investigations (eg, RCTs) are needed to test the best practices for self-neglect intervention and prevention. Despite the paucity of knowledge and empirical evidence with respect to the effective interventional strategies of self-neglect, a watchful approach might leave millions of older adults neglected and underserved in risky and dangerous situations. Hence, proactive actions and valuable suggestions from professionals with practical experience in the related fields might play a vital role in protecting the older people who are susceptible to the adverse outcomes of self-neglect.

\section{Disclosure}

The author reports no conflict of interest in this work.

\section{References}

1. Dong X, Gorbien M. Decision-making capacity: the core of self-neglect. J Elder Abuse Negl. 2005;17(3):19-36.

2. U.S. Department of Health \& Human Services. How can I recognize elder abuse? 2014. Available from: https://www.hhs.gov/answers/ programs-for-families-and-children/how-can-i-recognize-elder-abuse/ index.html. Accessed March 22, 2017.

3. Teaster PB, Dugar TA, Mendiondo MS, Abner EL, Cecil KA. The 2004 survey of state adult protective services: abuse of adults 60 years of age and older. The National Center on Elder Abuse; 2006. Available from: https://ncea.acl.gov/resources/docs/archive/2004-Survey-StAudit-APS-Abuse-18plus-2007.pdf. Accessed March 22, 2017.

4. Lee M, Kim K. Prevalence and risk factors for self-neglect among older adults living alone in South Korea. Int J Aging Hum Dev. 2014; 78(2):115-131.

5. Dong X, Simon MA, Mosqueda L, Evans DA. The prevalence of elder self-neglect in a community-dwelling population: hoarding, hygiene, and environmental hazards. J Aging Health. 2012;24(3):507-524.

6. Dong X, Simon MA, Evans DA. Prevalence of self-neglect across gender, race, and socioeconomic status: findings from the Chicago Health and Aging Project. Gerontology. 2012;58(3):258-268.

7. Dong X. Self neglect in an elderly community dwelling U.S. Chinese population: findings from the Population Study of Chinese Elderly in Chicago study. J Am Geriatr Soc. 2014;62(12):2391-2397.

8. Dong X, Simon MA. Elder self-neglect is associated with an increased rate of 30-day hospital readmission: findings from the Chicago Health and Aging Project. Gerontology. 2014;61(1):41-50.

9. Dong X, Simon MA. Association between elder self-neglect and hospice utilization in a community population. Arch Gerontol Geriatr. 2013; 56(1):192-198.

10. Dong X, Simon MA, Evans D. Elder self-neglect and hospitalization: findings from the Chicago Health and Aging Project. J Am Geriatr Soc. 2012;60(2):202-209.

11. Dong X, Simon M, Evans D. Elder self-neglect is associated with increased risk for elder abuse in a community-dwelling population: findings from the Chicago Health and Aging Project. J Aging Health. 2013;25(1):80-96.

12. Lachs MS, Williams CS, O'Brien S, Pillemer KA, Charlson ME. The mortality of elder mistreatment. JAMA. 1998;280(5):428-432.

13. Dong X. Do the definitions of elder mistreatment subtypes matter? Findings from the PINE Study. J Gerontol A Biol Sci Med Sci. 2014; 69(Suppl 2):S68-S75. 
14. Dong X. Sociodemographic and socioeconomic characteristics of elder self-neglect in an US Chinese aging population. Arch Gerontol Geriatr. 2016;64:82-89.

15. Burnett J, Dyer CB, Halphen JM, et al. Four subtypes of self-neglect in older adults: results of a latent class analysis. J Am Geriatr Soc. 2014; 62(6):1127-1132.

16. Dong X, Simon MA, Wilson RS, Mendes de Leon CF, Rajan KB, Evans DA. Decline in cognitive function and risk of elder self-neglect: finding from the Chicago Health Aging Project. J Am Geriatr Soc. 2010; 58(12):2292-2299.

17. Snowdon J. Uncleanliness among persons seen by community health workers. Psychiatr Serv. 1987;38(5):491-494.

18. Mardan H, Hamid T, Redzuan M, Ibrahim R. Correlate of self-care and self-neglect among community-dwelling older adults. Iran J Nurs Midwifery Res. 2014;19(7 Suppl 1):S71-S76.

19. Hurley M, Scallen E, Johnson H, De La Harpe D. Adult service refusers in the greater Dublin area. Ir Med J. 2000;93(7):208-211.

20. Dong X, Simon M, Fulmer T, Mendes de Leon CF, Rajan B, Evans DA. Physical function decline and the risk of elder self-neglect in a communitydwelling population. Gerontologist. 2010;50(3):316-326.

21. Abrams RC, Lachs M, McAvay G, Keohane DJ, Bruce ML. Predictors of self-neglect in community-dwelling elders. Am J Psychiatry. 2002; 159(10):1724-1730.

22. Dong XQ, Simon M, Evans D. Cross-sectional study of the characteristics of reported elder self-neglect in a community-dwelling population: findings from a population-based cohort. Gerontology. 2010; 56(3):325-334.

23. Dong X, Wilson RS, Mendes de Leon CF, Evans DA. Self-neglect and cognitive function among community-dwelling older persons. Int $J$ Geriatr Psychiatry. 2010;25(8):798-806.

24. Naik AD, Burnett J, Pickens-Pace S, Dyer CB. Impairment in instrumental activities of daily living and the geriatric syndrome of self-neglect. Gerontologist. 2008;48(3):388-393.

25. Turner A, Hochschild A, Burnett J, Zulfiqar A, Dyer CB. High prevalence of medication non-adherence in a sample of community-dwelling older adults with adult protective services-validated self-neglect. Drugs Aging. 2012;29(9):741-749.

26. Dong X, Simon M, Mendes de Leon C, et al. Elder self-neglect and abuse and mortality risk in a community-dwelling population. JAMA. 2009;302(5):517-526.

27. Dong X, Simon MA, Evans D. Prospective study of the elder self-neglect and emergency department use in a community population. Am J Emerg Med. 2012;30(4):553-561.
28. Dong X, Simon M. Elder self-neglect: implications for health care professionals. CGS J CME. 2013;3(1):25-28.

29. Schofield MJ. Screening for elder abuse: tools and effectiveness. In: Dong X, editor. Elder Abuse. Switzerland: Springer International Publishing; 2017:161-199.

30. Dyer CB, Kelly PA, Pavlik VN, et al. The making of a self-neglect severity scale. J Elder Abuse Negl. 2006;18(4):13-23.

31. Anetzberger GJ. Clinical management of elder abuse. Clin Gerontol. 2005;28(1-2):27-41.

32. Krug EG, Dahlberg LL, Mercy JA, Zwi AB, Lozano R. World report on violence and health. Geneva: World Health Organization; 2002.

33. Torke AM, Sachs GA. Self-neglect and resistance to intervention: ethical challenges for clinicians. J Gen Intern Med. 2008;23(11):1926-1927.

34. Kapp MB. Future directions in public policy relating to elder abuse. In: Dong X, editor. Elder Abuse. Switzerland: Springer International Publishing; 2017:693-707.

35. Naik AD, Lai JM, Kunik ME, Dyer CB. Assessing capacity in suspected cases of self-neglect. Geriatrics. 2008;63(2):24-31.

36. Social Care Institute for Excellence. Mental Capacity Act 2005 at a glance. 2009. Availbale from: http://www.scie.org.uk/mca/introduction/ mental-capacity-act-2005-at-a-glance. Accessed March 22, 2017.

37. MacMillan HL, Wathen CN, Jamieson E, et al; McMaster Violence Against Women Research Group. Screening for intimate partner violence in health care settings: a randomized trial. JAMA. 2009;302(5): 493-501.

38. Dong XQ. Elder abuse: systematic review and implications for practice. J Am Geriatr Soc. 2015;63(6):1214-1238.

39. Ploeg J, Fear J, Hutchison B, MacMillan H, Bolan G. A systematic review of interventions for elder abuse. J Elder Abuse Negl. 2009;21(3): 187-210.

40. Mosqueda L, Dong X. Elder abuse and self-neglect: "I don't care anything about going to the doctor, to be honest...". JAMA. 2011; 306(5):532-540.

41. Iowaaging.gov. Denial of critical care and self-neglect, a silent suffering press release. 2013. Available from: https://www.iowaaging.gov/ denial-critical-care-and-self-neglect-silent-suffering-press-release. Accessed March 22, 2017.

42. Office USGA. Elder justice: stronger federal leadership could enhance national response to elder abuse. 2011. Available from: http://www. gao.gov/new.items/d11208.pdf. Accessed January 25, 2017.

43. Dong X, Wang B. 2015 Rosalie Wolf Memorial Award Lecture: past, present, and future of elder abuse. J Elder Abuse Negl. 2016;28(4-5): 345-365.
Clinical Interventions in Aging

\section{Publish your work in this journal}

Clinical Interventions in Aging is an international, peer-reviewed journal focusing on evidence-based reports on the value or lack thereof of treatments intended to prevent or delay the onset of maladaptive correlates of aging in human beings. This journal is indexed on PubMed Central, MedLine,
Dovepress

CAS, Scopus and the Elsevier Bibliographic databases. The manuscript management system is completely online and includes a very quick and fair peer-review system, which is all easy to use. Visit http://www.dovepress. com/testimonials.php to read real quotes from published authors. 